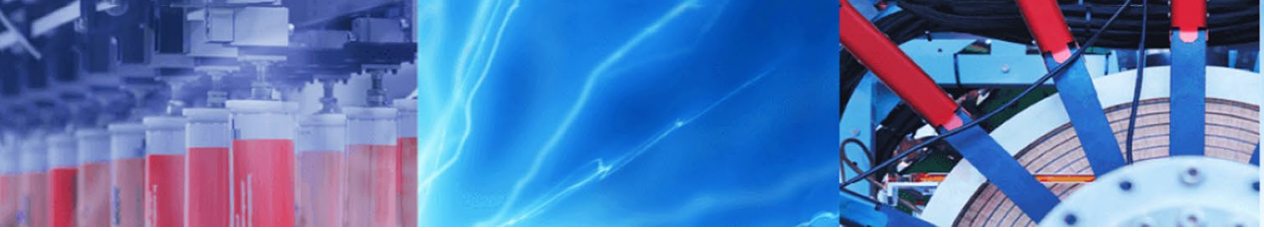

Research Article

\title{
Effect of Nickel-spinal-Ferrites on EMI shielding properties of polystyrene/polyaniline blend
}

\author{
M. Fayzan Shakir ${ }^{1}$ (1) $\cdot$ Asra Tariq $^{1} \cdot$ Z. A. Rehan ${ }^{1} \cdot$ Yasir Nawab $^{1} \cdot$ Iqra Abdul Rashid $^{1} \cdot$ Ayesha Afzal $^{1} \cdot$ Usama Hamid $^{1}$. \\ Fahad Raza ${ }^{1} \cdot$ Khadija Zubair $^{1} \cdot$ M. Saad Rizwan ${ }^{1} \cdot$ Saba Riaz $^{1} \cdot$ Arshad Sultan $^{1} \cdot$ Muhammad Muttaqi $^{1}$
}

Received: 28 January 2020 / Accepted: 14 March 2020 / Published online: 19 March 2020

(c) Springer Nature Switzerland AG 2020

\begin{abstract}
Magnetic and electrically conductive polymeric nanocomposites were fabricated using polystyrene (PS) as matrix, Nickel Ferrites (NiFe) as magnetic nanofiller and polyaniline (PANI) as electrically conductive nanofiller. Electromagnetic interference (EMI) shielding and infrared (IR) blocking are the main application of these nanocomposites. PANI and NiFe were successfully prepared by chemical and co-precipitation methods respectively. The successful fabrication of nanofillers was confirmed by the X-ray diffraction technique. DC conductivity and dielectric properties were first analyzed and a huge increase in both dielectric constant and DC conductivity was observed. Dielectric Constant seemed to be increased from 2.2 for PS to 5.5 for PS/PANI/NiFe composite. For the measurement of EMI shielding effectiveness (SE), Vector Network Analyzer was used in $0.1-20 \mathrm{GHz}$ frequency range. IR spectroscopy was used to measure IR transmission in near-infrared (NIR) region of 700-2500 nm wavelength range. PS film is transparent for both NIR waves and microwaves, by observing almost $90 \%$ transmission in the NIR range and about $-3 \mathrm{~dB}$ SE in the microwave region. IR transmission reduces to less than $0.5 \%$ for PS/PANI/NiFe composite in the whole NIR range. Also, in the microwave region, $-3 \mathrm{~dB}$ shielding enhanced to less than $-35 \mathrm{~dB}$ in a broad range of frequency from 0.1 to $20 \mathrm{GHz}$.
\end{abstract}

Keywords Polyaniline $\cdot$ Nickel Ferrites $\cdot$ EMI shielding $\cdot$ Polymer composites $\cdot$ Nanomaterials $\cdot$ Nanocomposites

\section{Introduction}

Nowadays the problem of electromagnetic interference (EMI) has increased very rapidly due to excessive use of electronic equipment's like electronic and telecommunication devices in different applications e.g. satellite broadcast systems $(11.5-12.1 \mathrm{GHz})$, radar $(12.3-18.1 \mathrm{GHz})$, LAN systems $(2.43,4.9,19,21,60 \mathrm{GHz})$ and mobile phones $(0.7-1.6 \mathrm{GHz})$ [1-3]. These cause serious health issues on the person working in the surrounding of equipment emitting EM wave. Different materials have been used for EMI shielding. These materials could be reflective and absorbing like carbon nanotubes (CNT), graphene, metallic and non-metallic. Intrinsically conducting polymers like polyaniline (PANI), polypyrrole (PPy) and polythiophene are also used as shielding materials. These materials are lightweight, easily processable and are of low cost [4].

Among all these materials PANI is the most widely used material due to its low cost, high conductivity, and easy processability. Due to poor mechanical properties of polyaniline, it is blended with different polymers like thermoplastic polyurethane (TPU), Styrene-Butadiene rubber (SBR), Nitrile rubber (NR) and Polyvinyl chloride (PVC) [5-9]. The PVC/PANI composites and blends showed higher conductivity when exposed to UV radiation [8]. These films are used in strain sensors, EMI shielding, corrosion-resistant devices, and chemical sensor applications. Polyaniline (PANI)/Graphene (GN) nanocomposites were

M. Fayzan Shakir, Fayzan.shakir93@gmail.com; $₫$ Asra Tariq, Asratariq23@gmail.com; $₫$ Z. A. Rehan, Zarehan@ntu.edu.pk| ${ }^{1}$ Department of Polymer Engineering, National Textile University, Faisalabad, Pakistan. 
prepared through the in-situ polymerization method. By increasing the graphene content EMI shielding effectiveness increased. These are used as lightweight materials in electronic devices to protect from radiations [10]. PANI in combination with PVC, PS and other thermoplastic polymers was used and observed very good EMI shielding properties $[6,7,11]$

Conventionally, materials having good magnetic properties i.e. permeability, high saturation magnetization like $\mathrm{Co}, \mathrm{Mn}, \mathrm{Zn}$, and Ba ferrites were used as microwave absorbing materials [1,12-15]. The magnetic ferrites are mostly used due to their low eddy current losses and high electrical resistivity. Conducting polymers is used to shield the waves generated from the electric source while the waves generated from an electromagnetic source at a lower frequency can be shielded effectively through the magnetic source. Due to this reason, different composites were fabricated from PANI and magnetic ferrites for EMI shielding purposes [16]. Blend of PS and PANI were also fabricated and found out to be very effective in the microwave region [17]. Blends of Nickel spinel ferrites (NiFe) $\mathrm{NiFe}_{2} \mathrm{O}_{4}$ and polymethyl methacrylate (PMMA) crystals were made as 3D network structure 80-250 nm Pore diameter for EMI shielding purpose through salt precipitation method. This network structure has greater reflection loss as compared to NiFe nanoparticles with the lightweight property as EMI shielding materials [18]. Barium ferrite and graphite were incorporated into PANI to make a conductive composite for EMI shielding purpose which shows shielding effectiveness $(-37.1 \mathrm{~dB})$ in $\mathrm{X}$-band $(8.2-12.4 \mathrm{GHz})$ range depends on dielectric loss [1].

During this research work, the nanocomposite based on PANI, Nickel spinal Ferrite (NiFe) and polystyrene (PS) were fabricated and characterized for EMI shielding application in microwave $(0.1-20 \mathrm{GHz})$ frequency region and also in NIR (700-2500 nm) wavelength range. The initial assessment was done by using electrical conductivity and dielectric properties and then tested for EMI shielding by Vector Network Analyzer (VNA) for the microwave region and IR spectroscopy for the NIR region. VNA results showed less than $-35 \mathrm{~dB}$ shielding effectiveness which is more than 99.9\%. IR spectroscopy reveals that nanocomposite films with a thickness of $0.25 \mathrm{~mm}$ showed less than $0.5 \%$ transmission in the whole NIR region.

\section{Materials}

Aniline was purchased from Sigma-Aldrich of 99\% purity, Ammonium Persulfate (APS) was obtained from DAEJUNG-Korea, Nickel Nitrate, Iron Nitrate, Sodium Hydroxide were also purchased from Sigma-Aldrich of $99 \%$ purity.
Chloroform from Fisher chemicals UK and Polystyrene were donated by Chawla enterprises Pakistan.

\section{Experiment}

\subsection{Preparation of Nickel Ferrites}

The co-precipitation method is used for the preparation of Nickel Ferrite (NiFe) [19]. 0.1 M and 0.2 M solution of nickel nitrate and iron nitrate were prepared and mixed together at $80^{\circ} \mathrm{C}$ temperature. Another $3 \mathrm{M}$ solution of $\mathrm{NaOH}$ was prepared and poured dropwise in the first solution keeping the temperature at $80^{\circ} \mathrm{C}$ with continuous stirring. The color of the solution changed to dark brown and precipitates started to appear as the 1st drop of $\mathrm{NaOH}$ solution touched the salt solution. The solution then stirred for $1 \mathrm{~h}$ at $80^{\circ} \mathrm{C}$ and then for $24 \mathrm{~h}$ at room temperature to complete the formation of precipitates. Stirring was then turned off and give settling time to precipitates. Washed with distilled water 5-6 times to get $7 \mathrm{pH}$ of solution. Precipitates were then filtered and dried at $700^{\circ} \mathrm{C}$ for $1 \mathrm{~h}$. Calcination was done in a muffle furnace at $850^{\circ} \mathrm{C}$ for $6 \mathrm{~h}$ and ground in a ball mill to get fine particle size. A flowchart is shown in Fig. 1 for a better understanding of the preparation steps of NiFe particles.

\subsection{Preparation of polyaniline (PANI)}

The chemical oxidative method was adopted for the preparation of electrically conductive "Emeraldine Salt" structure of polyaniline (PANI) [20]. Excessive formic acid was used as a dopant and also reaction medium for the polymerization of aniline. $2.4 \mathrm{~g}$ of APS was dissolved in formic acid at $50^{\circ} \mathrm{C}$ then place in an ice bath to reduce its temperature. The second solution of $1 \mathrm{ml}$ of aniline in $25 \mathrm{ml}$ of formic acid also prepared and placed in an ice bath. After achieving $0-5{ }^{\circ} \mathrm{C}$ temperature of both solutions, the APS solution poured dropwise in aniline solution. The greenish color of PANI particles started to appear just after the addition of APS solution and polymerization began. The solution was stirred for $3 \mathrm{~h}$ for complete polymerization and PANI precipitates formed and settled down at the bottom of the beaker. After the formation of PANI precipitates, it was filtered and vacuum dried at $300 \mathrm{mbar}$ pressure and $80{ }^{\circ} \mathrm{C}$ for $16 \mathrm{~h}$. A flowchart is shown in Fig. 2 for better understanding the preparation steps of PANI particles.

\subsection{Preparation of nanocomposite films}

Nanocomposite films were fabricated using solution casting method and chloroform was used as a solvent. PS is dissolved in chloroform by stirring for one hour. PANI 
Fig. 1 Preparation of Nickel Ferrite
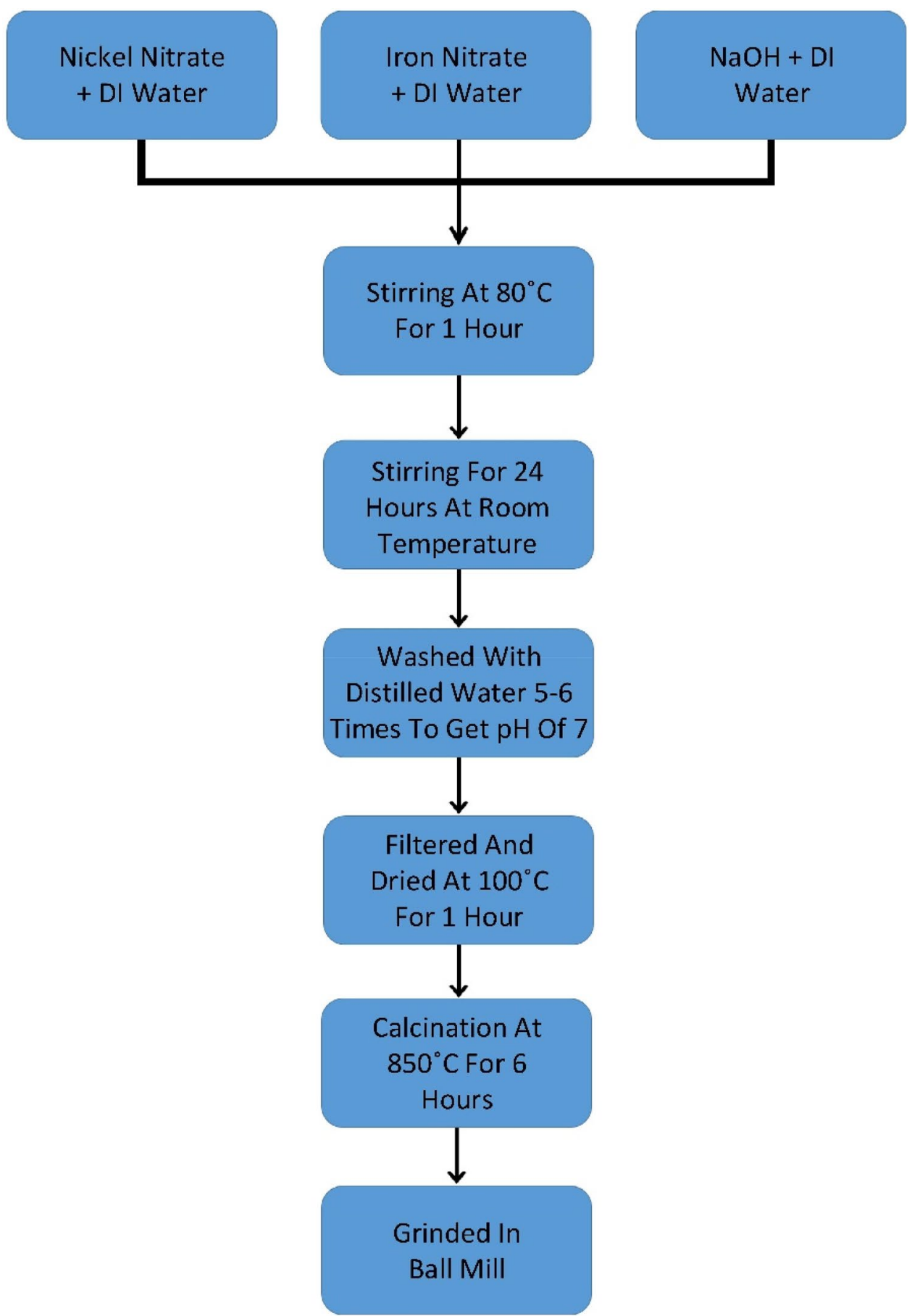

and NiFe particles were dispersed in chloroform separately and sonicated for $2 \mathrm{~h}$ to avoid agglomeration of particles. These three solutions mixed together in a way to get the desired compositions of nanocomposite films. Table 1 is showing the details of sample compositions. The whole solution was stirred for $24 \mathrm{~h}$, poured in a petri dish, placed on horizontal surface and dried at ambient condition for $5 \mathrm{~h}$ to get uniform thickness of the film and then dried in vacuum at $50{ }^{\circ} \mathrm{C}$ and $300 \mathrm{mbar}$ pressure overnight to remove traces of solvent left. The complete process is shown in Fig. 3. 250 to 300-micron film thickness was achieved and it was measured by both micrometer screw-gauge and SEM (JEOL-instrument JSM-6490A) shown in Fig. 4. 
Fig. 2 Preparation of polyaniline

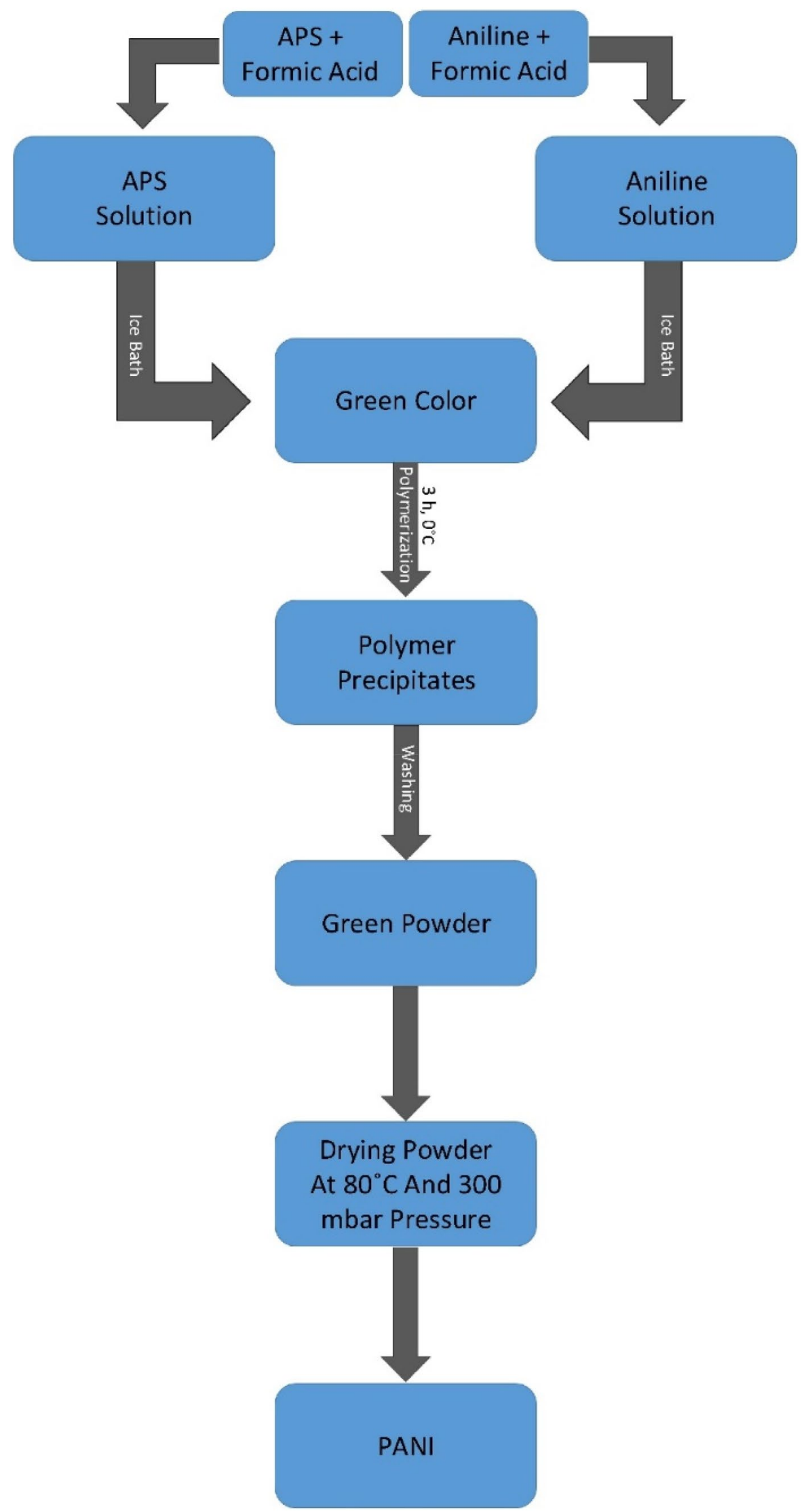


Table 1 List of samples and their composition

\begin{tabular}{llccc}
\hline Sample no & Sample name & PS wt\% & PANI wt\% & NiFe wt\% \\
\hline 1 & S1 & 100 & 0 & 0 \\
2 & S2 & 90 & 10 & 0 \\
3 & S3 & 80 & 20 & 0 \\
4 & S4 & 90 & 0 & 10 \\
5 & S5 & 80 & 0 & 20 \\
6 & S6 & 60 & 20 & 20 \\
\hline
\end{tabular}

Fig. 3 Preparation of nanocomposites

\section{Results and discussion}

\subsection{X-ray diffraction}

The x-ray diffraction technique was used for the confirmation of the successful polymerization of PANI. PANI is semicrystalline in nature and 2 peaks appear in the XRD pattern at $2 \theta=19^{\circ}$ and $2 \theta=25^{\circ}$ as shown in Fig. 5. These two peaks are corresponding to the perpendicular and parallel polymer chain periodicity $[21,22]$. Similar results for PANI were also found in the literature $[2,23-25]$

Figure 6 shows the XRD pattern of NiFe nanoparticles. Face centered cubic structure of NiFe was confirmed
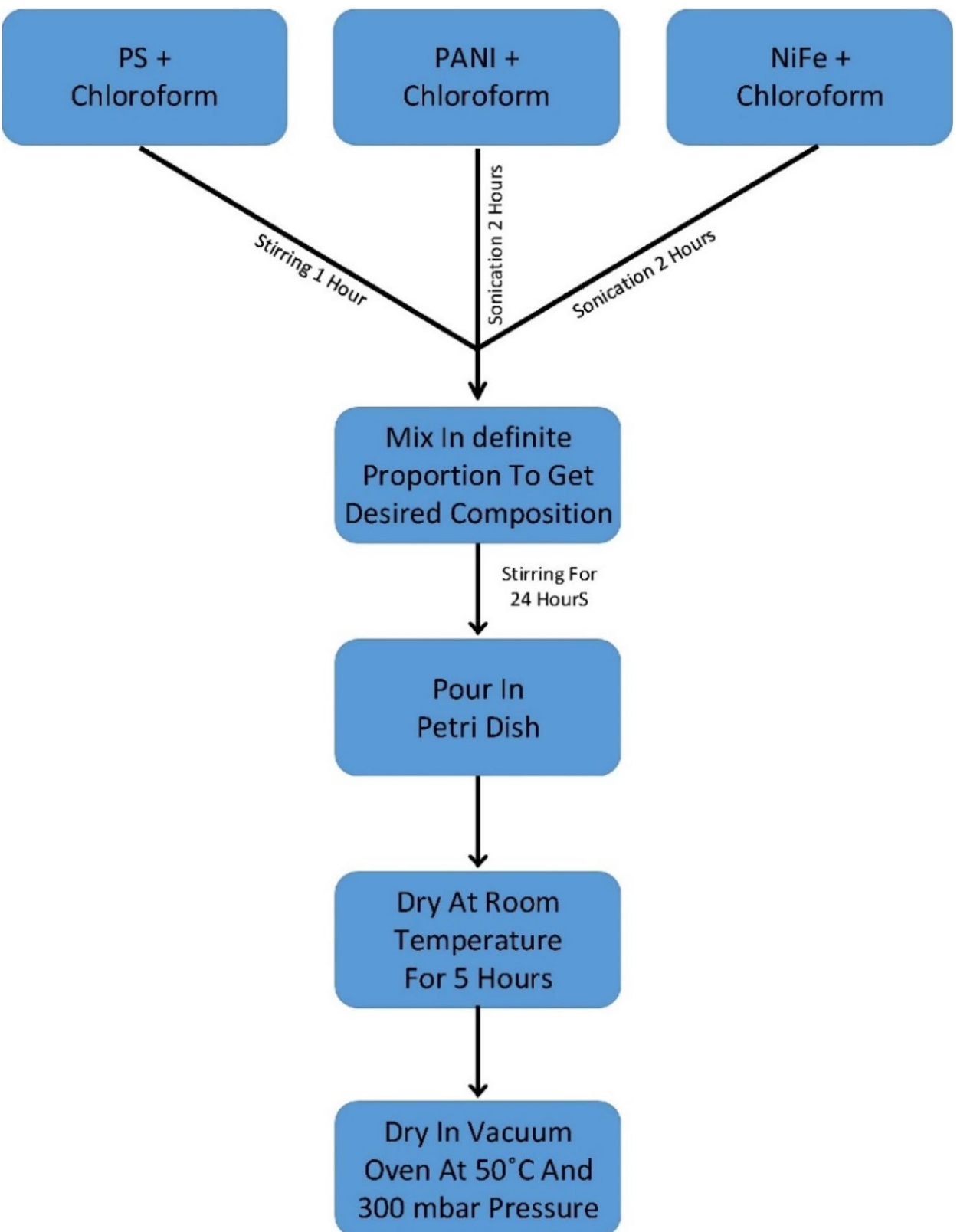

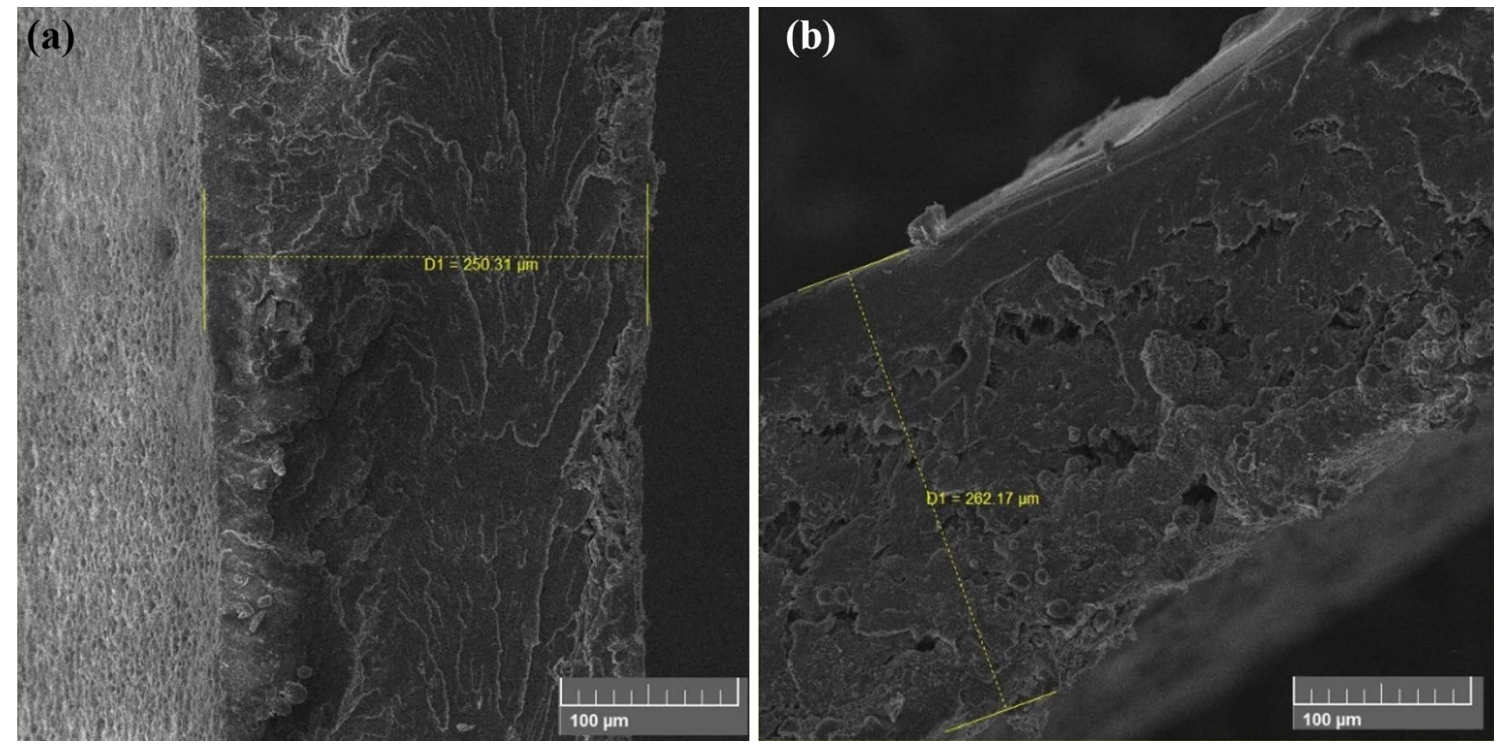

Fig. 4 Measurement of thickness of prepared samples by SEM
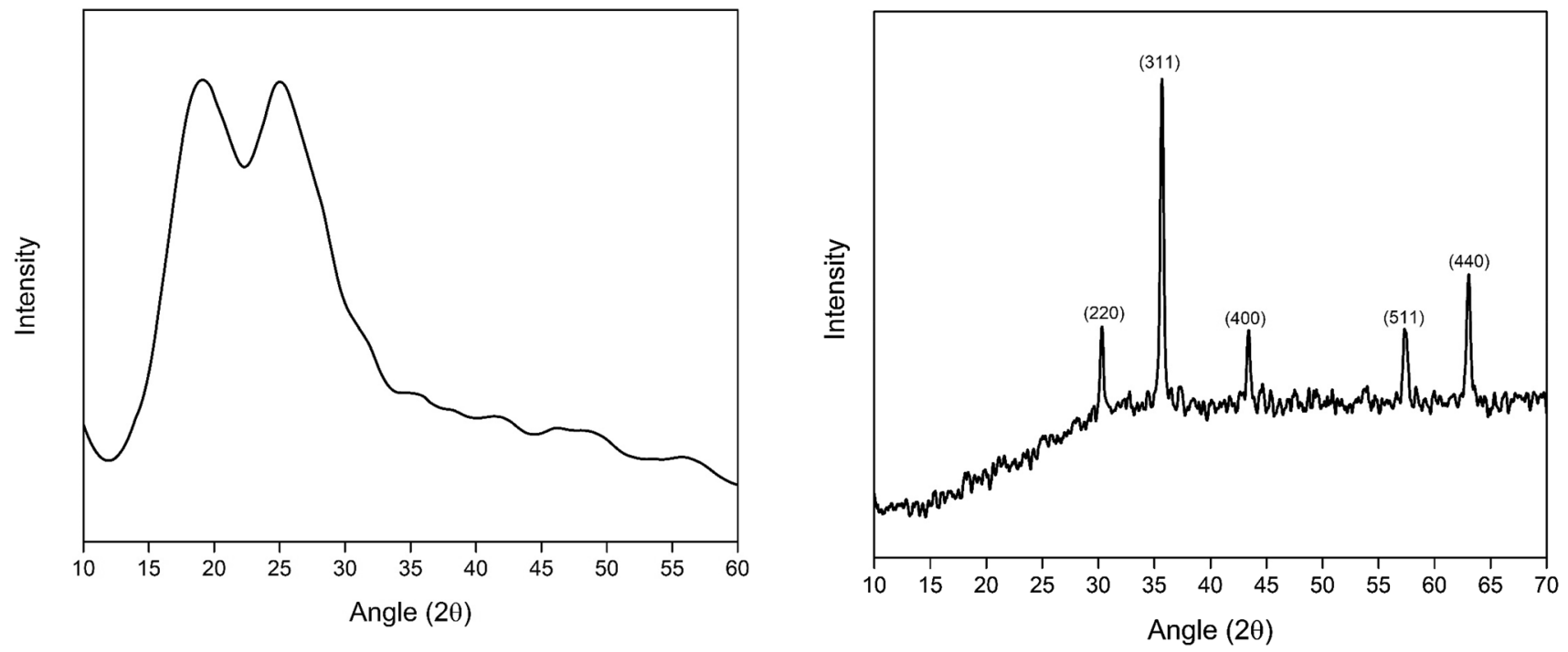

Fig. 5 X-ray diffraction pattern of polyaniline

through sharp peaks observed in the XRD pattern. It was examined that no secondary phase peaks were noticed. The sharp peaks appearing at $2 \theta=30.2^{\circ}, 35.7^{\circ}, 43.4^{\circ}, 57.4^{\circ}$, and at $63^{\circ}$ corresponds to (220), (311), (400), (511) and (440) planes of the spinel ferrite crystal lattice as discussed by T. Shanmugavel [14]. These values were matched with the standard JCPDS data. Similar results were shown by M Ali Ahmad and co. at temperature ranges from 500 to $1000^{\circ} \mathrm{C}$. Researchers showed that by increasing the temperature, the size of nanoparticle and crystallinity also increased. In addition, the samples which were heated at 400 and $500{ }^{\circ} \mathrm{C}$ showed superparamagnetic property but
Fig. 6 X-ray diffraction pattern of Nickel spinal Ferrites

at this temperature, some unstable phases also exist [19]. The same XRD results were also reported before [26].

Figure 7 shows the XRD pattern of prepared polymer nanocomposite films. As PS is amorphous in nature and no crystallinity can be found in its structure so its graph doesn't exhibit any prominent peak. As 10 and $20 \mathrm{wt} \%$ PANI is added in PS, characteristic single broad peak of PANI appeared at its exact positions indicating that it's only physically dispersed and there is no chemical interaction between both polymers, same is the case for S4 and S5. In sample S6, both PANI and NiFe were added in $20 \mathrm{wt} \%$, both of their characteristics peaks appeared and 


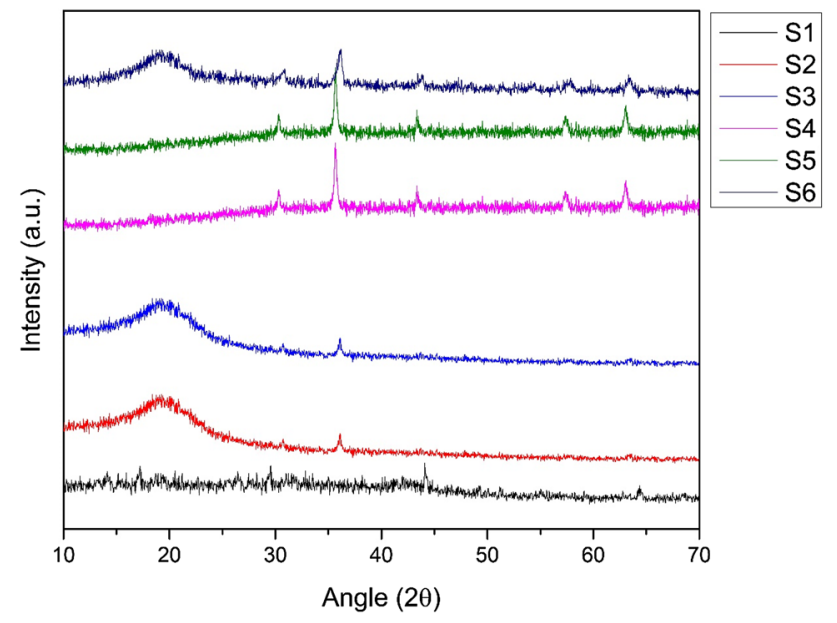

Fig. 7 X-ray diffraction pattern of polymer nanocomposites

neither a new peak appeared nor existing peaks disappeared confirming that their interaction is strictly physical not chemical.

\subsection{Scanning electron microscopy (SEM)}

Nanostructure of prepared polymer nanocomposites was observed by SEM (JEOL-instrument JSM-6490A).
Polymer films were frozen in liquid nitrogen and break it to get a fresh surface area to avoid chain elongation. As pure PS is completely amorphous in nature and thus no prominent features appeared on the SEM micrograph. SEM images of samples S1, S3, S5, and S6 are shown in Fig. 8. It is evident that both PANI and NiFe created nano level interconnected network structure inside the PS matrix and their shape and size is almost similar to each other. When both PANI and NiFe were added in $20 \mathrm{wt} \%$ each, the density of structure doubled keeping the shape and size intact. A mature and dense interconnected network structure is formed that is evident from Fig. $7 \mathrm{~d}$ and evident from high DC conductivity and EMI shielding explained in the next sections.

\subsection{DC conductivity}

2 probe method was employed to measure the DC conductivity of prepared sample films. Rectangular strips were cut with a dimension of $30 \mathrm{~mm} * 10 \mathrm{~mm}$. 2 probes with the voltage difference of $10 \mathrm{~V}$ were used at $20 \mathrm{~mm}$ separation as shown in Fig. 9. Using $10 \mathrm{~V}$ across the probes, current (I) flow from the film was obtained, by using the following 3 relationships, DC conductivity is calculated and reported in Table 2.
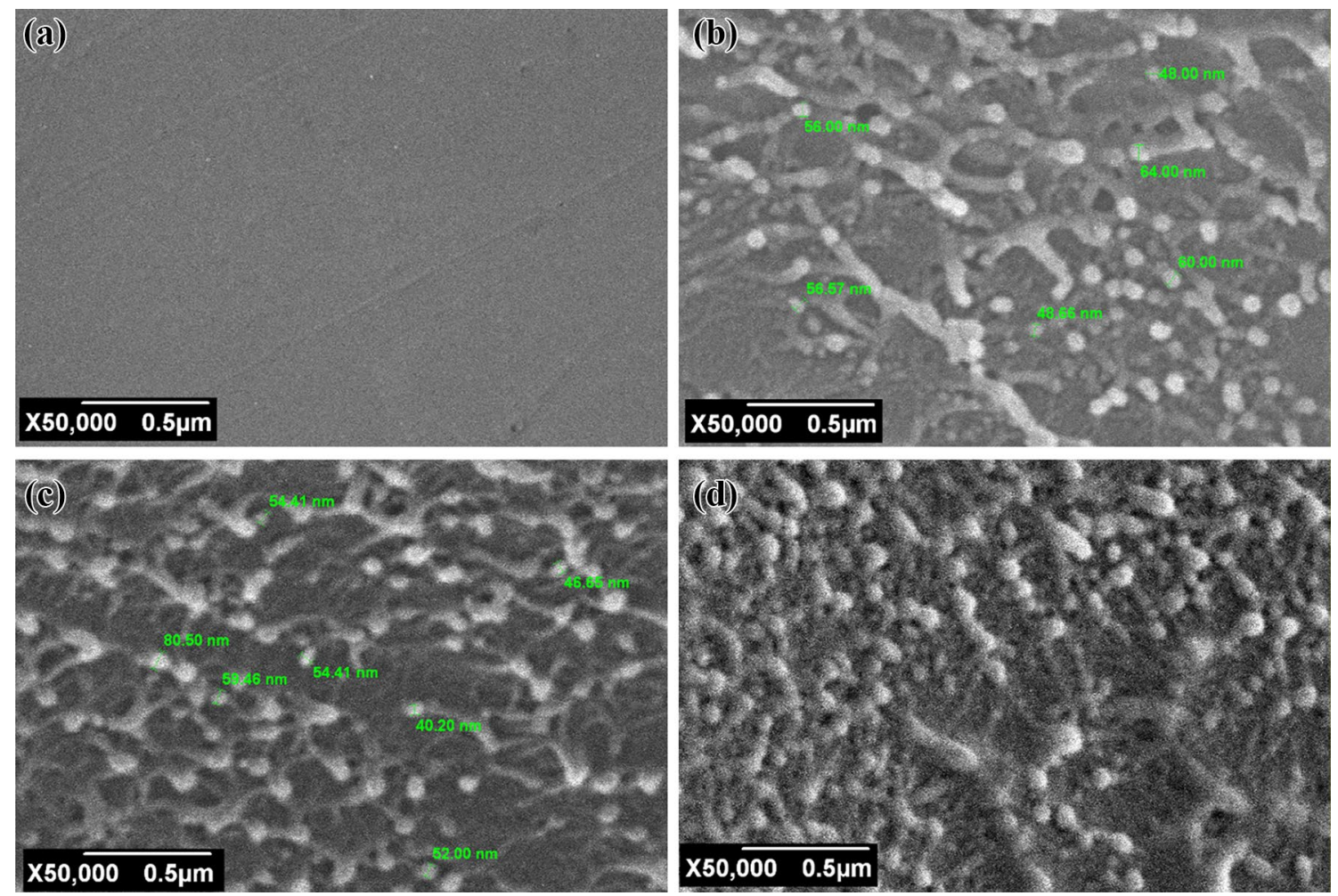

Fig. 8 SEM images of a S1, b S3, c S5, d S6 
Fig. 9 Schematic of 2 probe method for the measurement of DC conductivity

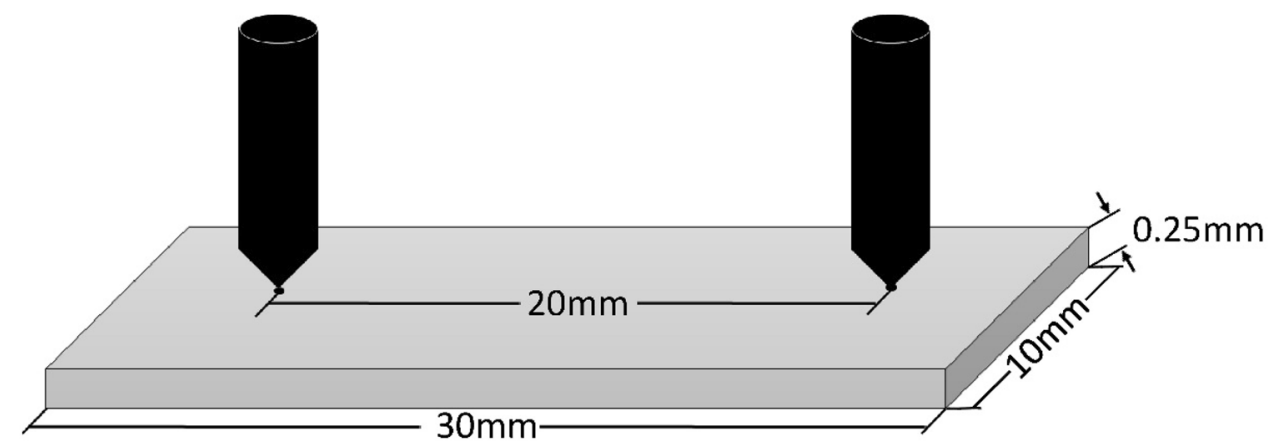

Table 2 DC conductivity values of prepared samples

\begin{tabular}{lll}
\hline Sample no & Sample name & $\begin{array}{l}\text { DC conduc- } \\
\text { tivity (S/cm) }\end{array}$ \\
\hline 1 & S1 & $1.3 \times 10^{-12}$ \\
2 & S2 & $2.9 \times 10^{-9}$ \\
3 & S3 & $6.7 \times 10^{-7}$ \\
4 & S4 & $1.8 \times 10^{-11}$ \\
5 & S5 & $2.1 \times 10^{-11}$ \\
6 & S6 & $8.4 \times 10^{-7}$ \\
\hline
\end{tabular}

$R=\frac{V}{l}$

$\rho=R \frac{A}{L}$

$\sigma=\frac{1}{\rho}$

where $\mathrm{V}, \mathrm{I}, \mathrm{A}, \mathrm{L}, \rho$, and $\sigma$ are applied voltage, current, area through which current is flowing, the distance between the probes, resistivity and DC conductivity respectively. Polystyrene is an insulator proved by its DC conductivity value. The increase in DC conductivity values by the addition of PANI clearly indicated that the interconnected network structure was formed by PANI that provided an optimum path for electrons to move throughout the film. DC conductivity is not that much affected with the addition of NiFe because NiFe nanoparticles don't have free electrons in its structure.

\subsection{Dielectric properties}

Dissipation factor (Tan $\delta$ ) and capacitance (C) were measured in the frequency range of $100 \mathrm{~Hz}$ to $3 \mathrm{MHz}$ using an impedance analyzer (Wayne Kerr 6500B). The following relationships were used to calculate dielectric constant $\left(\varepsilon^{\prime}\right)$, dielectric loss $\left(\varepsilon^{\prime \prime}\right)$ and $A C$ conductivity $\left(\sigma_{a c}\right)$ and are shown in Fig. 10.
$\varepsilon^{\prime}=C d \div A \varepsilon_{o}$

$\varepsilon^{\prime \prime}=\tan \delta * \varepsilon^{\prime}$

$\sigma_{\mathrm{ac}}=\omega \varepsilon_{o} \varepsilon^{\prime} \tan \delta$

$A, d$ and $C$ are the area, thickness, and capacitance of film respectively. $\omega$ and $\varepsilon_{0}$ are angular frequency and permittivity of free space respectively.

It was observed that with the addition of both PANI and $\mathrm{NiFe}$, all-dielectric parameters increased. In the case of PANI, the increase was seemed to have more prominent than NiFe because PANI is electrically conductive due to pi-electrons in its structure. While NiFe has only magnetic dipoles. Dielectric constant seemed to increase from 2 to 3.5 and 4 with the addition of 10 and 20 wt\% of PANI. The increase in AC conductivity confirms that PANI forms an interconnected network structure that enhances the electrical conductivity and also dielectric properties like a dielectric constant and dielectric loss. As discussed in DC conductivity. It is evident from the graph that $\varepsilon^{\prime}$ have very high values at a lower frequency and drop to constant value independent of frequency. As the electric field is applied, dipoles are induced in the sample. At low frequency, dipoles can reorient with changing electric field and so it showed high values of $\varepsilon^{\prime}$ but at high-frequency dipoles ceased on its position and gives a frequency-independent value. $\varepsilon^{\prime}$ values also depend on surface charge density. PANI/PS interface to act as an electrically conductive interface and have free electrons. The number of these surfaces increases as the PANI concentration increases and so $\varepsilon^{\prime}$ and $\varepsilon^{\prime \prime}$ increase with the addition of filler concentration as well. From sample S1 to S6, S6 has the highest concentration of reinforcement that is $20 \mathrm{wt} \% \mathrm{PANI}$ and 20 wt $\%$ NiFe nanoparticles and thus exhibit the highest values of the dielectric parameters.

\subsection{EMI shielding}

The coaxial cable method was employed for the measurement of EMI shielding effectiveness using a Vector 

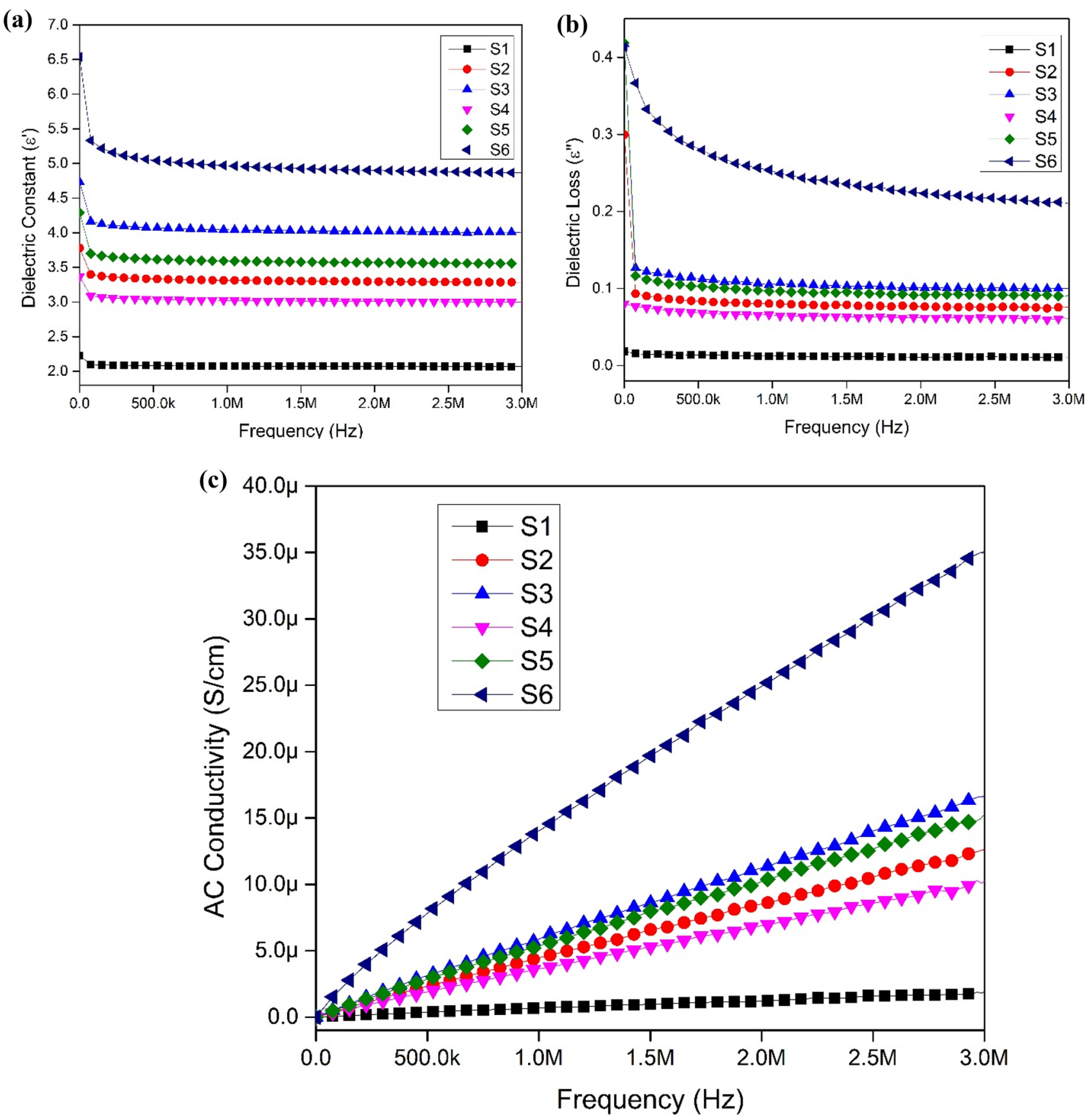

Fig. 10 a Dielectric constant, b dielectric loss and c AC conductivity of prepared samples

Network Analyzer with a maximum range of $-70 \mathrm{~dB}$. A donut-shaped sample was prepared with a $7 \mathrm{~mm}$ outer and $3 \mathrm{~mm}$ inner diameter with $0.25 \mathrm{~mm}$ thickness. A schematic diagram of a prepared sample for VNA is shown in Fig. 11. IR spectroscopy technique was used to measure the transmission of IR radiation of prepared samples in the NIR region $(700-2500 \mathrm{~nm})$ and results are shown in Fig. 12. S1 showed almost 90\% transmission allowing almost all the radiations to transmit, as $10 \mathrm{wt} \%$
PANI is added the transmission falls to $10 \%$ for sample S2. EMI theory describes that the EM wave reflects back when falls on an electrically conductive surface and absorbed when falls on magnetic surface. S4 sample showed almost $17 \%$ transmission, as it contained NiFe nanoparticle which is magnetic and so IR radiation must have been absorbed. For sample S3 and S5, the concentration of PANI and NiFe increased to $20 \mathrm{wt} \%$ from $10 \mathrm{wt} \%$, IR transmission falls to a very low value of less 
Fig. 11 Schematic diagram of the prepared sample for VNA. Side and front view

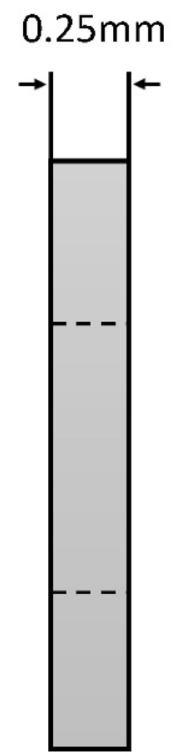

than $1 \%$ for S3 and $2 \%$ for S5. In the case of sample S6, it contained both PANI and NiFe and so it exhibited less than $0.5 \%$ transmission because of reflection from PANI/ PS interface and absorbance by the NiFe/PS interface.

Shielding effectiveness describes as the logarithmic ratio of incoming and transmitted energy of EM waves expressed as follows.

$S E=10 \log \left(\frac{E_{l}}{E_{T}}\right)$

Scattering parameters also called $S$-parameters $\left(\mathrm{S}_{11}, \mathrm{~S}_{12}, \mathrm{~S}_{21}\right.$, and $\left.\mathrm{S}_{22}\right)$ were obtained from VNA and by using the following equations, shielding effectiveness through reflection $\left(\mathrm{SE}_{\mathrm{R}}\right)$, shielding effectiveness through

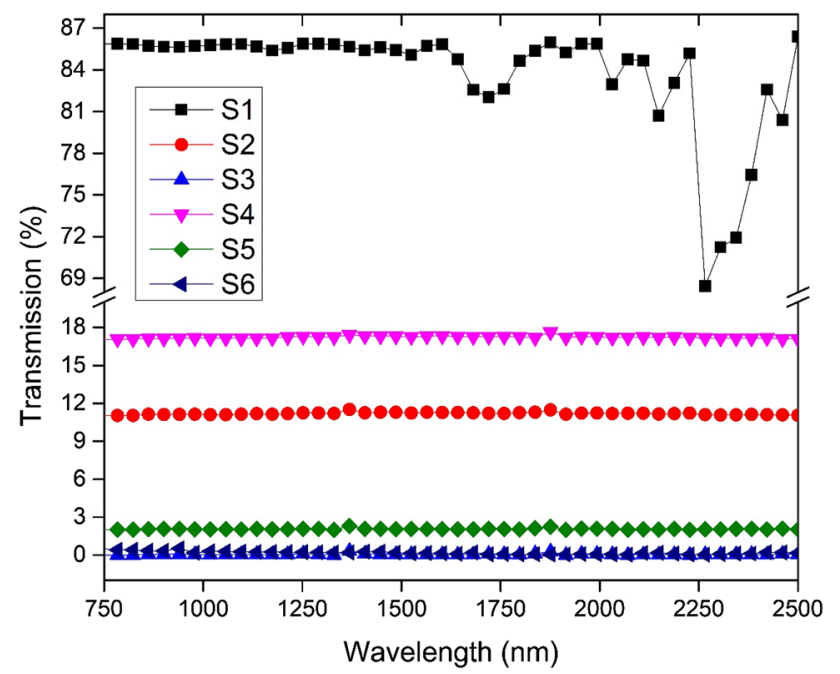

Fig. 12 IR transmission

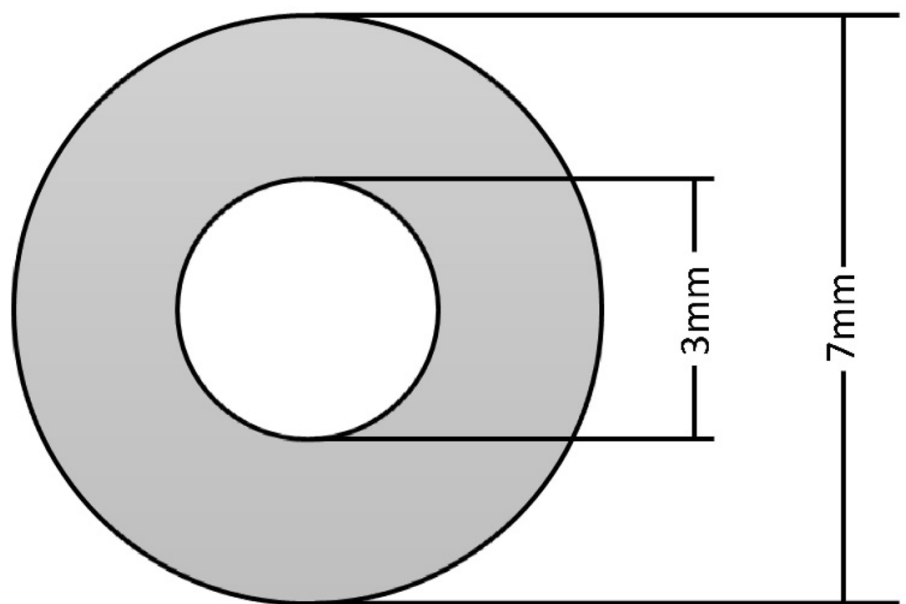

absorption $\left(\mathrm{SE}_{\mathrm{A}}\right)$ and total shielding effectiveness $\left(\mathrm{SE}_{\mathrm{T}}\right)$ were calculated.

$S E_{T}=S E_{R}+S E_{A}$

Both $\mathrm{SE}_{\mathrm{R}}$ and $\mathrm{SE}_{\mathrm{A}}$ are expressed as:

$S E_{R}=10 \log \frac{1}{1-\left|S_{11}\right|^{2}}$

$S E_{A}=10 \log \frac{1-\left|S_{11}\right|^{2}}{\left|S_{21}\right|^{2}}$

$\mathrm{SE}_{\mathrm{R}} \mathrm{SE}_{\mathrm{A}}$, and $\mathrm{SE}_{\mathrm{T}}$ are calculated and shown in Fig. 13.

These values coincide with EMI theory. Sample S1 didn't show any reflection or absorption loss because it is neither electrically conductive nor has any kind of magnetism. Sample $\mathrm{S} 2$ and $\mathrm{S} 3$ showed high values of $\mathrm{SE}_{\mathrm{R}}$ and $\mathrm{SE}_{\mathrm{A}}$, as $P A N I$ is electrically conductive and EM wave reflected back from the electrically conductive surface. PANI particles dispersed inside the film and some particles were present on the surface of the film as well. Particles that present on the surface gave higher $\mathrm{SE}_{\mathrm{R}}$ value but particles inside the film gave high $\mathrm{SE}_{\mathrm{A}}$. EM wave reflected back from the PS/PANI interface that is inside the film and the reflected wave before exiting the film interact again with another particle and so on. S2 and S3 samples gave high shielding efficiency of both types i.e. $\mathrm{SE}_{\mathrm{R}}$ and $\mathrm{SE}_{\mathrm{A}}$. In the case of $\mathrm{S} 4$ and $S 5$, Nickel spinel ferrites have magnetic domains and used as absorbing sites of $\mathrm{EM}$ wave, so $\mathrm{SE}_{\mathrm{A}}$ values of sample $\mathrm{S} 4$ and $\mathrm{S} 5$ are quite high while $\mathrm{SE}_{\mathrm{R}}$ is very low because of low electrical conductivity. $20 \mathrm{wt} \% \mathrm{NiFe}$ and $20 \mathrm{wt} \%$ PANI, both present in $\mathrm{S} 6$ and so this sample gave very high $\mathrm{SE}_{\mathrm{R}}$ vale that came from PS/PANI interface that presents on 

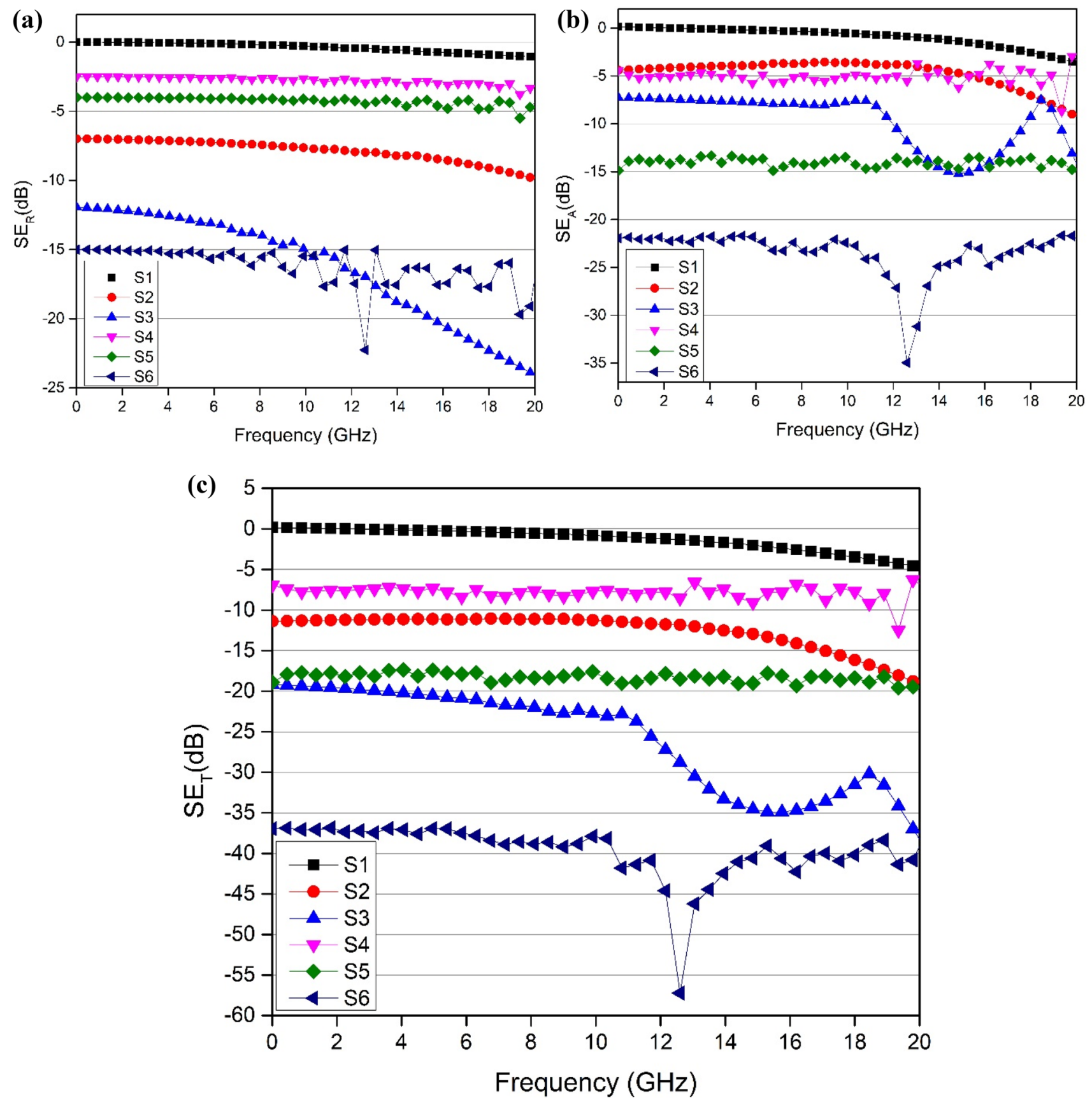

Fig. 13 a $\mathrm{SE}_{\mathrm{R}^{\prime}}, \mathbf{b} \mathrm{SE}_{\mathrm{A}}$ and $\mathbf{c} \mathrm{SE}_{\mathrm{T}}$ of prepared samples

the surface of the film and high $\mathrm{SE}_{\mathrm{A}}$ value came from PS/ PANI interfaces that were present inside the film and also from NiFe nanoparticles. $S 6$ gave $\mathrm{SR}_{\mathrm{T}}$ of less than $-35 \mathrm{~dB}$ in the broad range of frequency of $0.1-20 \mathrm{GHz}$ in which $\mathrm{SE}_{\mathrm{T}}$ values dropped even below to $-45 \mathrm{~dB}$ in $10-14 \mathrm{GHz}$ frequency range. $-10 \mathrm{~dB}$ is the threshold value for a good EMI shielding film, for polymeric composite, this value is achieved with very high filler loadings $30-40 \mathrm{wt} \%$ of fillers and then get $\mathrm{SE}_{T}$ value in range of -10 to $-20 \mathrm{~dB}$ and high shielding effectiveness of less than $-30 \mathrm{~dB}$ with filler loading odd $50-70$ wt $\%$ or from pure conductive/magnetic materials $[18,27,28]$.

According to EMI shielding theory, the EM wave reflects back when it falls on the electrically conductive surface and absorbed when falls on magnetic surface, both PANI and NiFe particles are dispersed inside the PS matrix and outer most surface mostly consisted of non-conductive PS. $\mathrm{SE}_{\mathrm{R}}$ is not very high indicating that most of the $\mathrm{EM}$ wave 


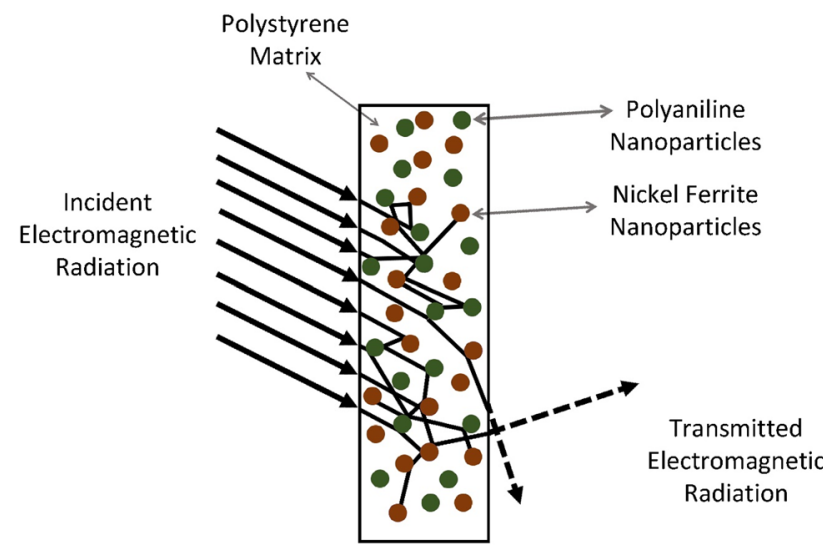

Fig. 14 Schematic of electromagnetic waves attenuation inside polymer composite film

penetrated inside the shielding film. Once the EM wave penetrates the shield then the electrically conductive PSPANI interfaces and magnetic PS-NiFe interfaces reflect and absorb EM wave through multiple reflections within 250 micron thin films as shown in Fig. 14.

The aim of this research was to get acceptable value of EMI shielding ( $-10 \mathrm{~dB}$ to $-20 \mathrm{~dB})$ with less than $20 \mathrm{wt} \%$ of filler loading and high shielding effectiveness (less than $-35 \mathrm{~dB}$ ) with no more than $40 \mathrm{wt} \%$ of filler loading. The thickness of the shielding film also plays an important role. Thickness is directly proportional to the shielding effectiveness. By using conventional macro-level fillers, these vales of shielding effectiveness achieved with 3-4 mm thickness [29]. Using new indigenously prepared nanolevel PANI and NiFe particles, less than $-35 \mathrm{~dB}$ shielding effectiveness achieved with $0.25 \mathrm{~mm}$ thickness of the film.

\section{Conclusion}

Magnetic nanoparticles "Nickel Spinal Ferrites" and electrically conductive form of "Polyaniline" were successfully prepared. Using polystyrene as a matrix, these nanofillers dispersed separately and in combination, tested for EMI shielding in the IR region and microwave region. DC conductivity and dielectric properties were first measured that indicated to have very good shielding effectiveness. Vector Network Analyzer and IR spectroscopy were used for the measurement of EMI shielding. It was observed to have shielding effectiveness less than $-35 \mathrm{~dB}$ in a broad spectrum of microwave region $(0.1-20 \mathrm{GHz})$, also have less than $0.5 \%$ transmission in the NIR region $(700-2500 \mathrm{~nm})$. Conventionally, EMI shields have high shielding effectiveness with very high filler loadings (50-70 wt\%) and 2-3 mm thickness. This research achieved a high EMI shielding with low filler loadings ( $40 \mathrm{wt} \%)$ and with a thickness of
$0.25 \mathrm{~mm}$ by using newly developed electrically conductive polymer and indigenously prepared nickel spinel ferrites.

\section{Compliance with ethical standards}

Conflict of interest The authors declare that they have no conflict of interest.

\section{References}

1. Gairola P, Gairola SP, Kumar V, Singh K, Dhawan SK (2016) Barium ferrite and graphite integrated with polyaniline as effective shield against electromagnetic interference. Synth Met 221:326-331

2. Saboor A, Khan AN, Cheema HM, Yaqoob K, Shafqat A (2016) Effect of polyaniline on the dielectric and EMI shielding behaviors of styrene acrylonitrile. J Mater Sci Mater Electron 27:9634-9641

3. Liu XG, Li B, Geng DY, Cui WB, Yang F, Xie ZG, Kang DJ, Zhang ZD (2009) (Fe, Ni)/C nanocapsules for electromagnetic-waveabsorber in the whole Ku-band. Carbon 47:470-474

4. Schmidt V, Domenech SC, Soldi MS, Pinheiro EA, Soldi V (2004) Thermal stability of polyaniline/ethylene propylene diene rubber blends prepared by solvent casting. Polym Degrad Stab 83:519-527

5. Rashid IA, Irfan MS, Gill YQ, Nazar R, Saeed F, Afzal A, Ehsan H, Qaiser AA, Shakoor A (2019) Stretchable strain sensors based on polyaniline/thermoplastic polyurethane blends. Polym Bull 77:1081-1093

6. Lakshmi K, John H, Mathew KT, Joseph R, George KE (2009) Microwave absorption, reflection and EMI shielding of PU-PANI composite. Acta Mater 57:371-375

7. Tian C, Du Y, Xu P, Qiang R, Wang Y, Ding D, Xue J, Ma J, Zhao $\mathrm{H}, \mathrm{Han} X$ (2015) Constructing uniform core-shell PPy@PANI composites with tunable shell thickness toward enhancement in microwave absorption. ACS Appl Mater Interfaces 7:20090-20099

8. Sevil UA, Güven O, Süzer S (1998) Spectroscopic investigation of onset and enhancement of electrical conductivity in PVC/PANI composites and blends by $\mathrm{Y}$-ray or UV irradiation. J Phys Chem B 102:3902-3905

9. Ameen S, Ali V, Zulfequar M, Mazharul Haq M, Husain M (2008) Electrical and spectroscopic characterization of polyanilinepolyvinyl chloride (PANI-PVC) blends doped with sodium thiosulphate. Phys B Condens Matter 403:2861-2866

10. Modak P, Kondawar SB, Nandanwar DV (2015) Synthesis and characterization of conducting polyaniline/graphene nanocomposites for electromagnetic interference shielding. Procedia Mater Sci 10:588-594

11. Koul S, Chandra R, Dhawan S (2000) Conducting polyaniline composite for ESD and EMI at $101 \mathrm{GHz}$. Polymer (Guildf) 41:9305-9310

12. Ashima A, Sanghi S, Agarwal A, Reetu R (2012) Rietveld refinement, electrical properties and magnetic characteristics of $\mathrm{Ca}-\mathrm{Sr}$ substituted barium hexaferrites. J Alloys Compd 513:436-444

13. Moujahid EM, Besse JP, Leroux F (2003) Poly(styrene sulfonate) layered double hydroxide nanocomposites. Stability and subsequent structural transformation with changes in temperature. J Mater Chem 13:258-264

14. Shanmugavel T, Gokul Raj S, Ramesh Kumar G, Rajarajan G, Saravanan D (2015) Cost effective preparation and characterization

\section{SN Applied Sciences}


of nanocrystalline nickel ferrites $\left(\mathrm{NiFe}_{2} \mathrm{O}_{4}\right)$ in low temperature regime. J King Saud Univ Sci 27:176-181

15. Liu $Y Y$, Zhang $X F$, Huang $H$, Lei JP, Dong $X L$, Wang WN, Lee CG, Lv B, Zhu XG (2006) Microwave absorption properties of the carbon-coated nickel nanocapsules. Appl Phys Lett 89:053115

16. Jiang J, Li L, Zhu M (2008) Polyaniline/magnetic ferrite nanocomposites obtained by in situ polymerization. React Funct Polym 68:57-62

17. Fayzan M, Abdul Rashid I, Tariq A, Nawab Y, Afzal A, Nabeel M, Naseem A, Hamid U (2019) EMI shielding characteristics of electrically conductive polymer blends of PS/PANI in microwave and IR region. J Electron Mater 49:1660-1665

18. Wang F, Wang $X$, Zhu J, Yang H, Kong $X$, Liu X (2016) Lightweight $\mathrm{NiFe}_{2} \mathrm{O}_{4}$ with controllable 3D network structure and enhanced microwave absorbing properties. Sci Rep 6:1-8

19. Aliahmad M, Noori M (2013) Synthesis and characterization of nickel ferrite nanoparticles by chemical method. Indian J Phys 87:431-434

20. Gomes EC, Oliveira MAS (2012) Chemical polymerization of aniline in hydrochloric acid $(\mathrm{HCl})$ and formic acid $(\mathrm{HCOOH})$ media. Differences between the two synthesized polyanilines. Am J Polym Sci 2:5-13

21. Huangfu Y, Ruan K, Qiu H, Lu Y, Liang C, Kong J, Gu J (2019) Fabrication and investigation on the PANI/MWCNT/thermally annealed graphene aerogel/epoxy electromagnetic interference shielding nanocomposites. Compos Part A Appl Sci Manuf 121:265-272

22. Joseph N, Varghese J, Sebastian MT (2017) In situ polymerized polyaniline nanofiber-based functional cotton and nylon fabrics as millimeter-wave absorbers. Polym J 49:391-399
23. Joseph N, Varghese J, Sebastian MT (2016) A facile formulation and excellent electromagnetic absorption of room temperature curable polyaniline nanofiber based inks. J Mater Chem C 4:999-1008

24. Fayzan $M$, Nawaz $A$, Khan R, Javed S, Tariq A, Azeem M, Riaz A, Shafqat A, Cheema HM, Aftab M, Ahmad I, Jan R (2019) Results in physics EMI shielding properties of polymer blends with inclusion of graphene nano platelets. Results Phys 14:102365

25. Shakir HMF, Tariq A, Afzal A, Abdul Rashid I (2019) Mechanical, thermal and EMI shielding study of electrically conductive polymeric hybrid nano-composites. J Mater Sci Mater Electron 30:17382-17392

26. Kavas H, Kasapoğlu N, Baykal A, Köseoğlu Y (2009) Characterization of $\mathrm{NiFe}_{2} \mathrm{O}_{4}$ nanoparticles synthesized by various methods. Chem Pap 63:450-455

27. Zhao B, Fan B, Xie Y, Zhang R (2015) Effect of particle sizes on the microwave absorption properties of monodispersed Ni submicrospheres. Optik (Stuttg) 126:4597-4600

28. Tehrani MK, Ghasemi A, Moradi M, Alam RS (2011) Wideband electromagnetic wave absorber using doped barium hexaferrite in Ku-band. J Alloys Compd 509:8398-8400

29. Jan R, Bilal Khan M, Khan Z (2012) Synthesis and electrical characterization of "carbon particles reinforced epoxy-nanocomposite" in Ku-band. Mater Lett 70:155-159

Publisher's Note Springer Nature remains neutral with regard to jurisdictional claims in published maps and institutional affiliations. 